- Notes -

\title{
Selective Recovery of Dysprosium and Neodymium Ions by a Supported Liquid Membrane Based on Ionic Liquids
}

\author{
Yuzo BABA, Fukiko KUBOTA, Noriho KAMIYA and Masahiro GOTO* \\ Department of Applied Chemistry, Graduate School of Engineering, \\ Kyushu University, Fukuoka 819-0395, Japan \\ (Received January 18, 2011; Accepted February 10, 2011)
}

\begin{abstract}
Selective permeation of rare earth metal ions (Dy and $\mathrm{Nd}$ ) against ferric ion ( $\mathrm{Fe}$ ) was conducted by an ionic liquid-based supported liquid membrane (SLM). A novel extractant $N, N$-dioctyldiglycol amic acid (DODGAA) was employed as the mobile carrier because the DODGAA is readily soluble in ionic liquids such as 1-octyl-3-methylimidazolium bis(trifluoromethanesulfonyl)imide $\left(\left[\mathrm{C}_{8} \mathrm{mim}\right]\left[\mathrm{Tf}_{2} \mathrm{~N}\right]\right)$ and shows good selectivity to the rare earth metal ions and efficient stripping behavior. Quantitative transport of Dy and Nd was successfully achieved through the SLM impregnated with the $\left[\mathrm{C}_{8} \mathrm{mim}\right]\left[\mathrm{Tf}_{2} \mathrm{~N}\right]$ containing DODGAA. Ferric ions were transported at the $10 \%$ level, and Dy and $\mathrm{Nd}$ were selectively recovered to the receiving phase. The results suggested a potential use of the SLM system proposed in this study for the recovery of the rare earth metals from leaching magnet scrap which produces leach liquor containing a large amount of $\mathrm{Fe}$.
\end{abstract}

\section{Introduction}

In recent years, there has been a great demand for rare earth metals, which are essential for high-tech industries. The stable supply of such metals has been a concern for Japan because almost all of the metal resoruces are produced in one country. Now industrial wastes or scraps incorporating rare earth metals such as fluorescent materials for lamps or CRT, permanent magnets for the motors of hybrid vehicles or home appliances and so on have been highlighted as valuable secondary resources [1-5]. The used products contain a variety of and a large amount of metal impurities. For example, Nd-Fe-B sintered magnets contain more than $20 \mathrm{wt} \% \mathrm{Nd}, 4 \sim 5 \%$ Dy and not less than $60 \% \mathrm{Fe}$ [4]. Solvent extraction is one of the most promising techniques for the separation of the rare earth metals. However, a more efficient 
process has been required for the recovery of valuable metals from such resources.

Liquid membranes are one of the most efficient separation systems. A liquid membrane, which consists of feed and receiving phases separated by an immiscible phase, i.e. the liquid membrane phase, allows simultaneous extraction and stripping at each side of the membrane [6,7]. In supported liquid membranes (SLMs), the liquid membrane phase containing a carrier which selectively binds a target metal ion is impregnated into the pores of a microporous thin polymer film which is placed between the feed and receiving phases. Key requirements for the successful separation of metal ions through SLMs are not only a good choice of the mobile carrier, but also the establishment of stable liquid membranes which will withstand long-term operation. However, in SLMs using a conventional organic solvent as the liquid membrane phase, instability of the membrane has been a problem for their practical use. In this decade, ionic liquids have been highlighted as solvents for liquid-liquid extraction and liquid membrane separation due to their unique properties [7,8,9], and studies on their application for metal separation have increased $[3,10,11]$. Recently, we developed a stable membrane system using an ionic liquid such as $\left[\mathrm{C}_{8} \mathrm{mim}\right]\left[\mathrm{Tf}_{2} \mathrm{~N}\right]$ as the membrane phase, and succeeded in the selective recovery of rare earth metals employing the novel extractant DODGAA as the carrier suitable for the ionic liquid [12].

In the present study, we investigated selective permeation of the rare earth metals, Dy and $\mathrm{Nd}$, over Fe through a liquid membrane constructed by utilizing the ionic liquid $\left[\mathrm{C}_{8} \operatorname{mim}\right]\left[\mathrm{Tf}_{2} \mathrm{~N}\right]$ for the application to the recovery of the rare earth metals from magnet scrap.

\subsection{Reagents}

\section{Experimental}

The imidazolium-based ionic liquid (IL), 1-octyl-3-methylimidazolium bis(trifluoromethanesulfonyl)imide (abbreviated as $\left.\left[\mathrm{C}_{8} \mathrm{mim}\right]\left[\mathrm{Tf}_{2} \mathrm{~N}\right]\right)$ was synthesized as described in a previous paper [10]. DODGAA was synthesized from diglycolic anhydride and di-octylamine through a one step reaction [13,14]. The chemical structures of DODGAA and $\left[\mathrm{C}_{8} \operatorname{mim}\right]\left[\mathrm{Tf}_{2} \mathrm{~N}\right]$ are shown in Fig. 1. All other

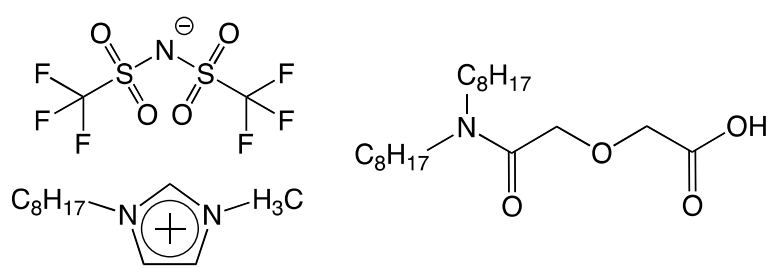
$\left[\mathrm{C}_{8} \operatorname{mim}\right]\left[\mathrm{Tf}_{2} \mathrm{~N}\right]$ DODGAA

Figure 1. Molecular structure of the reagents. reagents were of analytical grade.

\subsection{Extraction equilibria}

Extracting phases were prepared by dissolving DODGAA in $\left[\mathrm{C}_{8} \operatorname{mim}\right]\left[\mathrm{Tf}_{2} \mathrm{~N}\right]$. Aqueous solutions, $0.1 \mathrm{mM}$ each were prepared by dissolving the nitrate salts of neodymium, dysprosium and ferric ion. The $\mathrm{pH}$ values were adjusted using $0.1 \mathrm{M}$ sodium acetate, $0.1 \mathrm{M}$ acetic acid and $0.1 \mathrm{M}$ nitric acid solutions. 
Equal volumes of the IL and aqueous solutions were mixed and gently shaken at $298 \mathrm{~K}$ for 24 hours. The metal ion concentrations in the aqueous solutions were determined using an ICP-atomic emission spectrometer (ICP-AES; Optima 5300, Perkin Elmer Co.) [10].

\subsection{Preparation of the SLM}

The supported liquid membrane (SLM) was prepared by immersing a hydrophobic porous polyvinylidene fluoride film (PVDF; Millipore Corp., pore size $0.45 \mu \mathrm{m}$ and thickness $125 \mu \mathrm{m}$ ) in $\left[\mathrm{C}_{8} \mathrm{mim}\right]\left[\mathrm{Tf}_{2} \mathrm{~N}\right]$ containing $10 \mathrm{mM}$ DODGAA [12].

The surface morphologies of the untreated PVDF and the prepared SLM were imaged using a scanning electron microscopy (SEM; SS-550, Shimadzu Co.).

\subsection{Membrane separation}

The schematic diagram of the liquid membrane apparatus is shown in Fig. 2. An aqueous feed phase containing $\mathrm{Nd}$, Dy and $\mathrm{Fe}$ at $0.1 \mathrm{mM}$ each at $\mathrm{pH} 4$ was prepared in the same manner as for the extraction equilibrium measurements. $1 \mathrm{M}$ nitric acid was used as the aqueous receiving phase solution. A transport experiment was performed using a glass cell unit that held the membrane (effective area $5 \mathrm{~cm}^{2}$ ) between two independent $55 \mathrm{~cm}^{3}$ compartments for the feed phase and the receiving phase [12]. The transport experiment was initiated by filling each compartment with each solution and samples were periodically withdrawn from each phase. The metal concentrations of the samples were determined by ICP-AES.

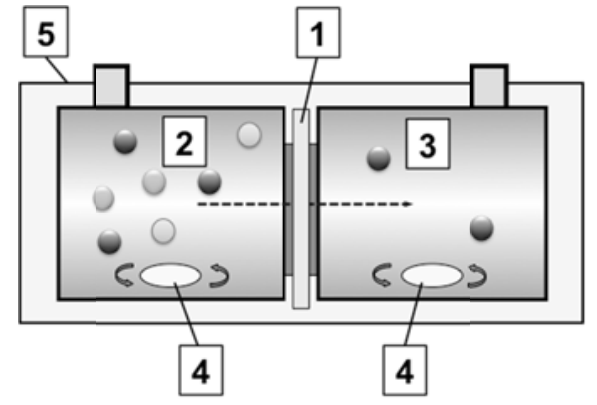

1. supported liquid membrane

2. feed phase

3. receiving phase

4. stirring bar

5. water bath

Figure 2. Schematic diagram of the liquid membrane apparatus.

\section{Results and discussion}

\subsection{Extraction behavior of neodymium(III), dysprosium(III) and ferric ion(III) with DODGAA}

Figure 3(a) shows the extraction of Dy, Nd and Fe with DODGAA from the aqueous phase to the $\left[\mathrm{C}_{8} \operatorname{mim}\right]\left[\mathrm{Tf}_{2} \mathrm{~N}\right]$ phase. As can be seen in Fig. 3(a), the rare earth metal ions, Dy and Nd, were selectively extracted over $\mathrm{Fe}$ under the experimental conditions. It was found that $\mathrm{Fe}$ ion was preferentially extracted over the rare earth metals with the conventional extractant PC-88A in the organic solvent system. Although the extractability of Fe was suppressed in the ionic liquid system, the extractability of rare earth metals with PC-88A still could not exceed that for Fe (data not shown). Thus it was concluded that DODGAA was useful as an extractant for the separation of rare earth metals from aqueous metal mixtures containing a relatively large amount of ferric ion. 

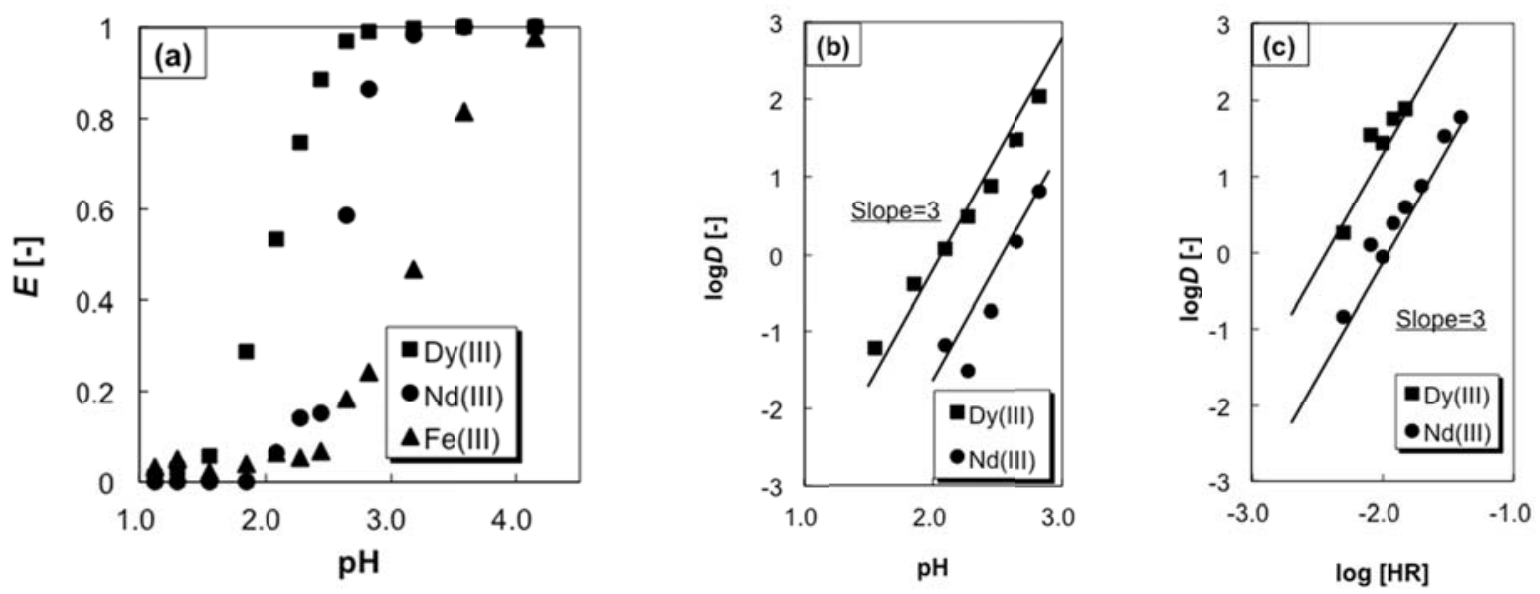

Figure 3. Extraction behavior of Dy(III), Nd(III) and Fe(III) with DODGAA in [ $\left.\mathrm{C}_{8} \operatorname{mim}\right]\left[\mathrm{Tf}_{2} \mathrm{~N}\right]$.

(a) Effect of $\mathrm{pH}$ on the extractant ratio $\left([\mathrm{DODGAA}]_{0}=10 \mathrm{mM}\right)$. (b) Effect of $\mathrm{pH}$ on the distribution ratio $\left([D O D G A A]_{0}=10 \mathrm{mM}\right)$. (c) Effect of the extractant concentration on the distribution ratio $(\mathrm{pH}=2.5)$.

Figure $3(\mathrm{~b})$ shows the effect of $\mathrm{pH}$ on the logarithmic distribution ratio, $\log D\left(D=[\mathrm{M}]_{\mathrm{IL}} /[\mathrm{M}]_{\mathrm{aq}}\right)$, for Dy and Nd. Straight lines of slope 3 were obtained from the plots, therefore this indicated that the extraction proceeded via a proton exchange mechanism as described in a previous paper for $\mathrm{Y}$ and $\mathrm{Eu}[12]$. A linear relationship with a slope 3 was also obtained between $\log D$ and DODGAA concentration (Fig.3(c)). The details of the extraction mechanism of rare earth metals with DODGAA in the ionic liquid system will appear in another article [15]. However, from the results in Fig. 3, the extraction equilibria for Dy and Nd can be expressed as follows:

$$
\mathrm{M}^{3+}+3 \mathrm{HR}_{\mathrm{IL}} \rightleftarrows \mathrm{MR}_{3, \mathrm{IL}}+3 \mathrm{H}^{+}, K_{\mathrm{ex}} \quad(\mathrm{M}=\mathrm{Nd} \text { and } \mathrm{Dy}, \mathrm{HR}=\text { DODGAA })
$$

Based on Eq.(1), extraction equilibrium constants for Dy and Nd was evaluated $6.26 \times 10^{-1}$ and $2.35 \times 10^{-2}$ respectively. The separation of Dy and $\mathrm{Nd}$ seems to be also possible after separation from Fe.

\subsection{SEM images of membrane surface}

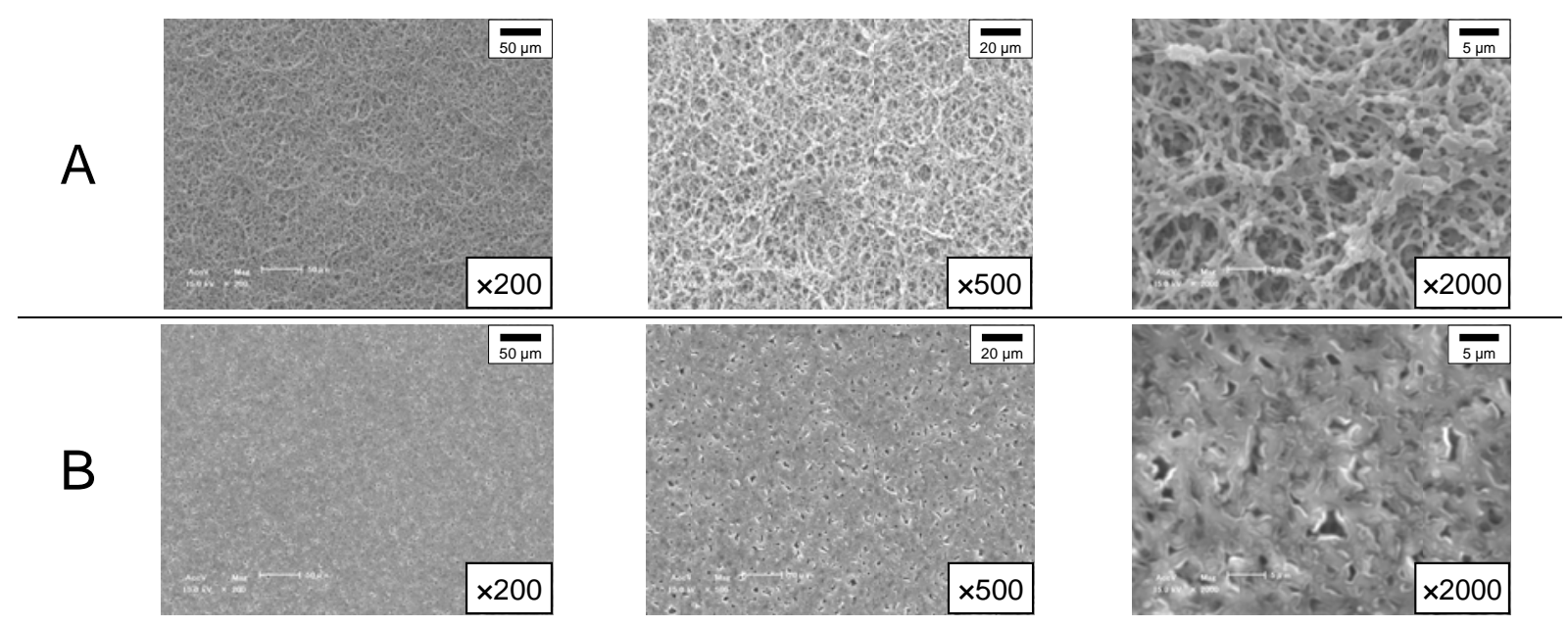

Figure 4. SEM micrographs of (A) untreated PVDF and (B) the SLM prepared using $\left[\mathrm{C}_{8} \operatorname{mim}\right]\left[\mathrm{Tf}_{2} \mathrm{~N}\right]$. 
SEM micrographs of untreated PVDF and that after the preparation of the SLM are respectively shown in Fig. 4 (A) and (B). As shown in Fig. 4(A), the micro porous structure of the untreated membrane film can be seen. Figure 4(B) is the image for PVDF after immersing in the $\left[\mathrm{C}_{8} \mathrm{mim}\right]\left[\mathrm{Tf}_{2} \mathrm{~N}\right]$. The porous structure of the liquid membrane appears to be well filled with the $\left[\mathrm{C}_{8} \operatorname{mim}\right]\left[\mathrm{Tf}_{2} \mathrm{~N}\right]$.

\subsection{Selective membrane separation of neodymium(III) and dysprosium(III) from ferric ion(III)}

Figure 5 shows the permeation behavior of Dy and $\mathrm{Nd}$ through the membrane impregnated with $\left[\mathrm{C}_{8} \mathrm{mim}\right]\left[\mathrm{Tf}_{2} \mathrm{~N}\right]$ containing $10 \mathrm{mM}$ DODGAA. Dy and $\mathrm{Nd}$ were successfully transported from the feed phase to the receiving phase against their concentration gradients, and quantitative recovery was achieved. It would appear that the extraction reaction expressed by Eq. (1) took place at the aqueous-ionic liquid interface of the extracting side of the liquid membrane, and at the interface of the receiving side. The rare earth metal ions in the membrane phase are immediately released to the receiving phase according to the reverse reaction of Eq. (1) (Fig. 6). Meanwhile, the transportation of ferric ion was only 10\% level. Therefore, this system is useful for the separation of rare earth metals from $\mathrm{Fe}(\mathrm{III})$, which is generally difficult in conventional solvent extraction.

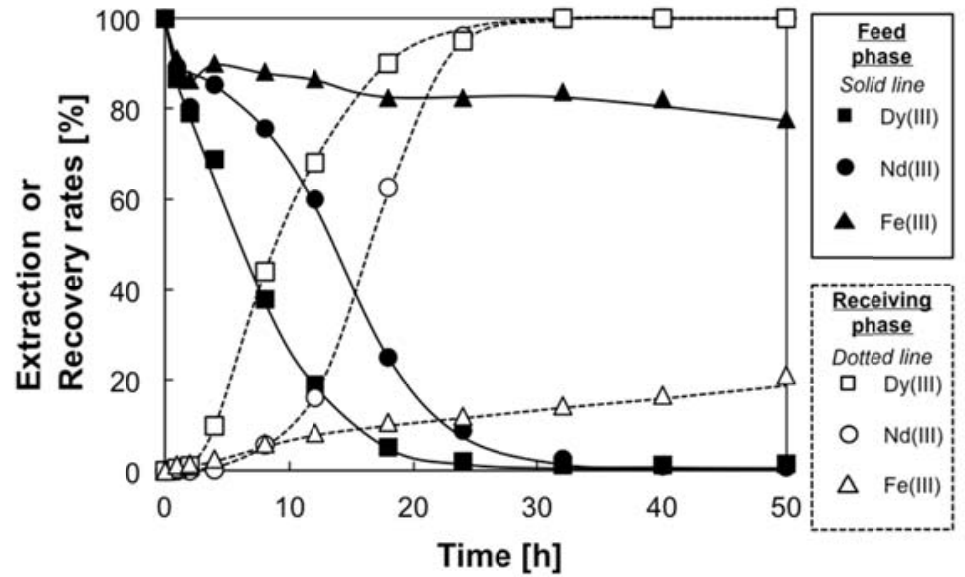

Figure 5. Rates of change in the metal ion concentrations in the feed and receiving phases during the IL-based SLM operation.

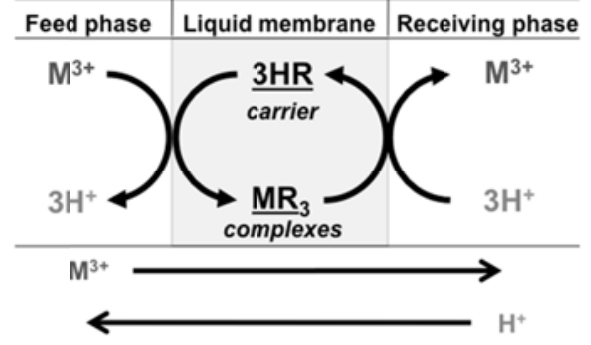

Figure 6 . The extraction mechanism in the liquid membrane.

More than $99 \%$ purification of the rare earth metals from ferric ion is achievable through two steps of the membrane operation at a rough estimate under the present extraction conditions. The result suggests that several operation steps would enable the recovery of the rare earth metals from the solution containing higher levels of Fe than the rare earth metals, such as a leaching solution of magnet scrap. A liquid membrane based on an ionic liquid such as $\left[\mathrm{C}_{8} \mathrm{mim}\right]\left[\mathrm{Tf}_{2} \mathrm{~N}\right]$ was proved to be stable during more than 140 hours of operation in a previous paper [12]. 


\section{Conclusions}

In order to apply an ionic liquid based SLM system to the recovery of rare earth metals from a magnet scrap, we have investigated the permeation of Dy and Nd through an SLM impregnated with the ionic liquid, $\left[\mathrm{C}_{8} \mathrm{mim}\right]\left[\mathrm{Tf}_{2} \mathrm{~N}\right]$. A novel extractant DODGAA was found to have a higher selectivity for Dy and $\mathrm{Nd}$ compared with Fe, unlike conventional extractants such as PC-88A. Then used DODGAA as the mobile carrier. Quantitative transport of Dy and $\mathrm{Nd}$ through the membrane was achieved, whereas the metal impurity $\mathrm{Fe}$ was only slightly transferred to the receiving phase. The membrane was quite stable during the operation. The results suggested that the SLM system would be applicable for the recovery of Dy and Nd from the leaching solution of magnet scrap containing ferric ion as an impurity.

\section{Acknowledgements}

This work was supported by Grants for Research and Technology Development on Waste Management (K22020) from the Ministry of Environment, Japan and a Grant-in-Aid for Science Research (No. 21360383) from the Ministry of Education, Science, Sports and Culture of Japan.

\section{References}

1) K. Shimojo, F. Kubota, T. Oshima, M. Goto. S. Furusaki, Kagaku Kogaku Ronbunshu, 26, 506 (2000).

2) T. Nakamura, S. Nishihama, K. Yoshizuka, Solv. Extr. Res. Dev. Jpn, 14, 105 (2007).

3) Y. Baba, F. Kubota, N. Kamiya, M. Goto, J. Chem. Eng. Jpn., 44, DOI: 10.1252/jcej.10we279 (2011).

4) K. Miura, M. Itoh, K. Machida, J. Alloys Compounds. 466, 228 (2008).

5) L. E. O. C. Rodrigues, M. B. Mansur, J. Power Sources, 195, 3735 (2010).

6) F. Kubota, M. Goto, Solv. Extr. Res. Dev. Jpn, 12, 11 (2005).

7) R. Fortunato, C.A.M. Afonso, M.A. Reis, J.G. Crespo, J. Membr. Sci., 242, 197 (2004).

8) X. Han, D. W. Armstrong, Acc. Chem. Res., 40, 1079 (2007).

9) D. Han, K. H. Row, Molecules, 15, 2405 (2010).

10) F. Kubota, Y. Koyanagi, K. Nakashima, K. Shimojo, N. Kamiya, M. Goto, Solv. Extr. Res. Dev. Jpn., 15, 81 (2008).

11) K. Morita, N. Hirayama, K. Morita, H. Imura, Analytica Chimica Acta, 680, 21 (2010).

12) F. Kubota, Y. Shimobori, Y. Koyanagi, K. Shimojo, N. Kamiya, M.Goto, Anal. Sci., 26, 289 (2010).

13) H. Naganawa, K. Shimojo, H. Mitamura, Y. Sugo, J. Noro, M. Goto, Solv. Extr. Res. Dev. Jpn, 14, 151 (2007).

14) K. Shimojo, H. Naganawa, J. Noro, F. Kubota, M. Goto, Anal. Sci., 23, 1427 (2007).

15) F. Kubota, Y. Shimobori, Y. Baba, Y. Koyanagi, K. Shimojo, N. Kamiya, M.Goto, J. Chem. Eng. Jpn., 44, DOI: 10.1252/jcej.11we005 (2011). 